Vu Minh Thanh,

Institute of Chemistryand Material,

E-mail:vmthanh222@yahoo.com

\title{
REMOVAL OF Cr(III) FROM AQUEOUS SOLUTION BY LOW-COST $\mathrm{Fe}_{3} \mathrm{O}_{4}$ /TALC NANOCOMPOSITE
}

Abstract. The $\mathrm{Fe}_{3} \mathrm{O}_{4} /$ Talc nanocomposite was synthesized by using the chemical co-precipitation method. The reaction was carried out under a nonoxidizing oxygen-free environment. The $\mathrm{Cr}^{3+} \mathrm{ad}-$ sorption by $\mathrm{Fe}_{3} \mathrm{O}_{4} /$ Talc nanocomposite was carried out in batch conditions. The kinetic data of the adsorption reactions were described by pseudo-first-order and pseudo-second-order equations and intraparticle diffusion models. Results showed that the pseudo-order was fitted to the kinetic data. The isotherms of adsorption were also studied using Langmuir and Freundlich equations in linear forms. It found that the Langmuir equation showed better linear correlation with the experimental data than the Freundlich. The maximum monolayer coverage, $\mathrm{q}_{\max }$ at $297 \mathrm{~K}$ were found to be $54.35 \mathrm{mg} / \mathrm{g}$.

Keywords: nanocomposite, Langmuir and Freundlich equations, cleaning of drains.

\section{Introduction}

Heavy metal ions pollutants exis in the aqueous has increased over the last some decades due to industrial. In which, Cr is widely used in industry as plating, alloying, tanning of animal hides, inhibition of water corrosion, textile dyes and mordants, pigments, ceramic glazes, refractory bricks, ... [1]. Due to this wide anthropogenic use of $\mathrm{Cr}$, the consequential environmental contamination increased and has become an increasing concern in the last years [2]. The toxic ions enter the food chain and then the human body [3]. Water pollution by heavy metals is one of the most serious threat to public health and the environment. Because heavy metals are non-biodegradable and are more difficult to remediate [4]. Some in place treatment technologies are mainly based on physicochemical, electrochemical or advanced oxidation processes. Physicochemical processes include membrane filtration, chemical precipitation, ion-exchange, and adsorption. Electrocoagulation, electroflotation, and electrodeposition are categorized under the name of electrochemical methods [5]. Recently, nanotechnology is a practical approach in treating wastewaters, too. Among all these possible methods, those with costeffective, environment-friendly and no further pollutants features are the favorites [6].
In recent years, the use of natural compounds [7], agricultural waste material [8], industry [9], it is inexpensive to make adsorbent materials to remove heavy metals of interest. Such as, Talc $\left[\mathrm{Mg}_{3} \mathrm{Si}_{4} \mathrm{O}_{10}(\mathrm{OH})_{2}\right]$, is a natural compound widely used in the form of a fine powder in several industrial products. The structure of talc is the well-known 2:1 ( T-O-T) layer configuration consisting of an octahedral magnesium $(\mathrm{Mg})$ coordinated sheet (O) sandwiched between two tetrahedral silicon $(\mathrm{Si})$ coordinated sheets $(\mathrm{T})$ [10]. Talcum powder $(30-50 \mu \mathrm{m})$ for preparing the nanocomposite was supplied by Talcum powder Phu Tho - Viet Nam. Talc-based materials have been synthesized and applied as adsorbent materials for removing toxic agents such as heavy metals [11], wastewater containing organic dyes [12].

In this work, the adsorption isotherm, kinetic of $\mathrm{Cr}^{3+}$ ion onto $\mathrm{Fe}_{3} \mathrm{O}_{4} /$ Talc nanocomposite produced from Talc (Phu Tho - Viet Nam) were studied.

\section{Experiments}

\section{1. $\mathrm{Fe}_{3} \mathrm{O}_{4} /$ Talc nanocomposite}

The material is synthesized by the co-precipitation method on the talc layers in an inert atmosphere, with the 1:2 ratio of $\mathrm{Fe}^{2+} / \mathrm{Fe}^{3+}$. The synthesis process is carried out as document [13] with talc 
powder of Vietnam (particle size $\leq 50 \mu \mathrm{m}$; density $2.4 \mathrm{~g} / \mathrm{cm}^{3}$; main components include: $\mathrm{SiO}_{2}: 56.8 \%$; $\mathrm{MgO}: 31.5 \%$; $\left.\mathrm{Fe}_{2} \mathrm{O}_{3}: 3.5 \%\right)$.

The materials structure was determined by Field Emission Scanning Electron Microscope method (FESEM, Jeol 6610LA, Japan). Nitrogen adsorptiondesorption isotherms were performed at $77 \mathrm{~K}$ in Tristar 3000-Micromeritics equipment, USA, using static adsorption proceduce. Samples were degassed at $80^{\circ} \mathrm{C}$ and $10^{-6}$ Torr for minimum $12 \mathrm{~h}$ prior to analysis. BET surface areas were calculated from the linear part of BET plot according to IUPAC recommendation. Pore size distributions of the samples were calculated via the conventional BJD model and magnetic properties by measuring with a vibrating-sample magnetometer.

\subsection{Studying the adsorption of $\mathrm{Cr}^{3+}$ ion by} $\mathrm{Fe}_{3} \mathrm{O}_{4} /$ Talc nanocomposite

The process of adsorption of $\mathrm{Cr}^{3+}$ ion in aqueous solution is carried out in interrupted conditions at a temperature of 297 K. Stirring speed of $200 \mathrm{v} / \mathrm{min}$, the initial concentration of $\mathrm{Cr}^{3+}$ is varied within 10 200 ppm. The solution's $\mathrm{pH}$ was surveyed from 4-7, the volume of $\mathrm{Cr}^{3+}$ solution was $50 \mathrm{ml}$, the amount of adsorbent used was $0.1 \mathrm{~g}$. The concentration of before and after $\mathrm{Cr}^{3+}$ adsorption is calculated by oxidizing the sample to determine the total $\mathrm{Cr}$ concentration and subtracting $\mathrm{Cr}$ (VI) concentration, in which $\mathrm{Cr}$ (VI) is determined by colorimetric method. when chelating with 1.5-Diphenylcarbazide, the total $\mathrm{Cr}$ was determined by FAAS method on the ContrAA 700 device of Analytikjena at a wavelength of $359.34888 \mathrm{~nm}$; Acetylene/air stream; $50 \mathrm{~mm}$ lamp height.

Adsorption capacity of $\mathrm{Fe}_{3} \mathrm{O}_{4} /$ Talc nanocomposite is calculated by the formula [14]:

$$
q=\frac{\left(C_{o}-C_{t}\right) \cdot V}{m}
$$

Where, $V$ is the volume of solution (1); $\mathrm{m}$ is the mass of adsorbent $(\mathrm{g}) ; \mathrm{C}_{0}, \mathrm{C}_{t}$ are $\mathrm{Cr}^{3+}$ concentrations in the initial solution and at time t respectively $(\mathrm{mg} / \mathrm{l})$;

inetics of the adsorption process is studied by basing on the pseudo-first-order adsorption kinetics equation $\left(B_{1}\right)$ inlinearform: $\ln \left(q_{e}-q_{t}\right)=\ln \left(q_{e}\right)-k_{1} . t(2)$, where: $k_{1}\left(\mathrm{~min}^{-1}\right)$ is the rate constant of the pseudofirst-order adsorption kinetics process; $q_{e}, q_{t}$ are the adsorption capacities at the equilibrium time and time t. The pseudo-second-order adsorption kinetics equation in linear form: $\frac{t}{q_{t}}=\frac{t}{q_{e}}+\frac{1}{k_{2} \cdot q_{e}^{2}}$ (3), Where: $\mathrm{k}_{2}$ ( $\mathrm{mg} / \mathrm{g} \cdot \mathrm{min}$ ) is the rate constant of the adsorption kinetics process $[15 ; 16]$. Diffusion kinetics equation: $\ln \left(q_{t}\right)=\ln \left(k_{D}\right)+0.5 \cdot \ln (\mathrm{t})(4)$, where: $k_{D}\left(\mathrm{mg} / \mathrm{g} .(\mathrm{min})^{0.5}\right)$ is the diffusion coefficient [17]. Elovich equation: $q_{t}=\frac{1}{\beta} \ln (\alpha \beta)+\frac{1}{\beta} \ln (t)$ (5) where: $\alpha$ and $\beta$ are constants of Elovich - type equation [18].

\section{RESULTS AND DISCUSSION}

\subsection{Properties of $\mathrm{Fe}_{3} \mathrm{O}_{4} / \mathrm{Talc}_{\mathrm{c}}$ nanocomposite}

The surface properties, porosity or pore size is one of the factors to evaluate the adsorption capacity of the material. Figure 1 is the FESEM image of $\mathrm{Fe}_{3} \mathrm{O}_{4} /$ Talc nanocomposite.

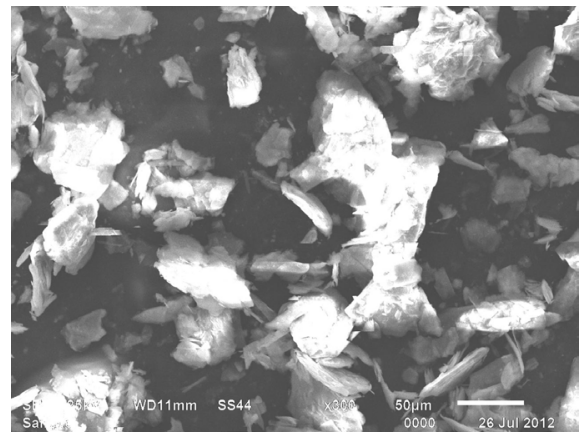

(a)

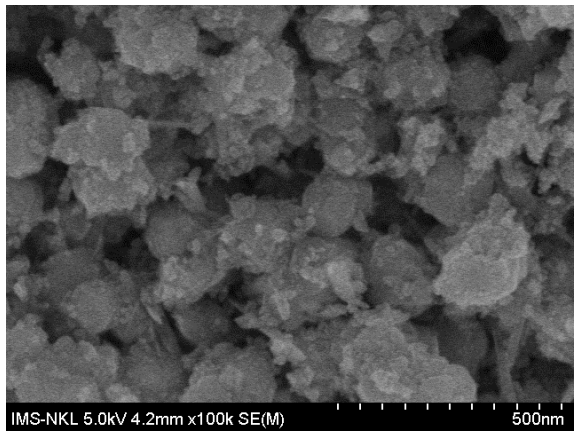

(b)

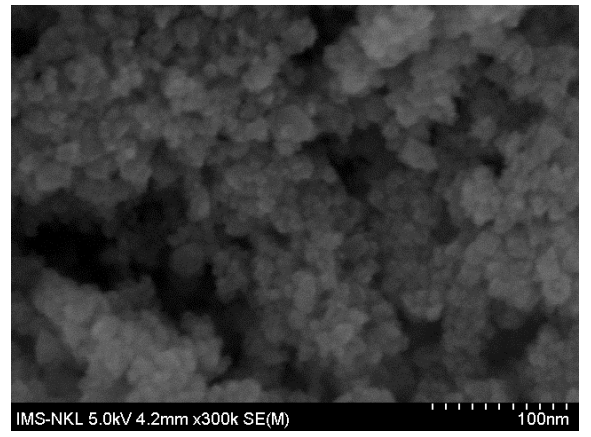

(c)

Figure 1. Scanning electron microscopy image of Talc (a) and the synthesized $\mathrm{Fe}_{3} \mathrm{O}_{4} / \mathrm{Talc}(\mathrm{b}, \mathrm{c})$ 
From the results of (Figure 1), it is shown that Talc surface material has particle sizes in the range of $30-50 \mathrm{~nm}$, cubic particles are less uniform and have smooth surface. Nanocomposite materials at different magnifications (Fig. 1.b, 1.c), had distribution of

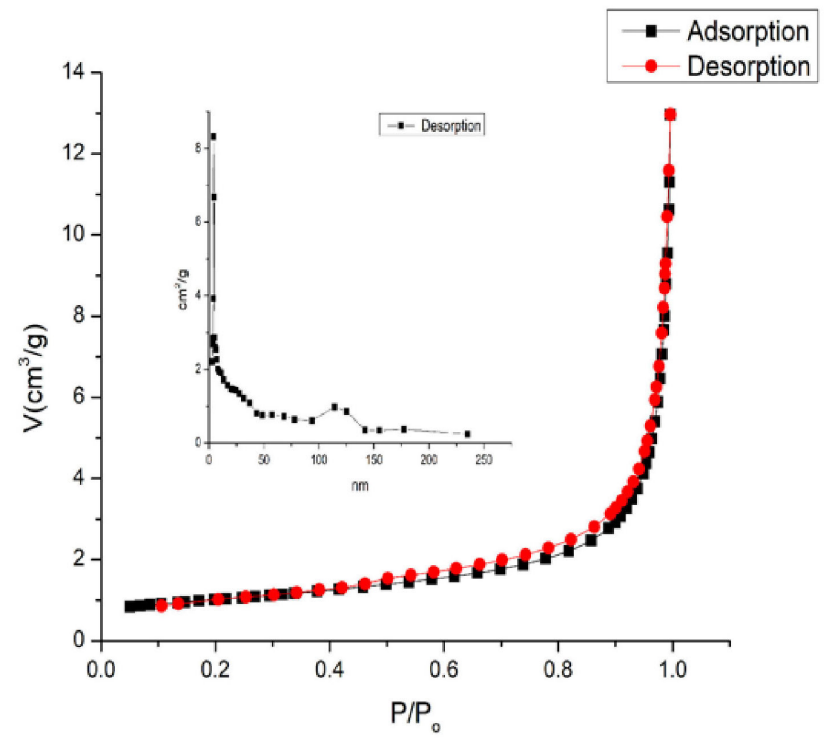

$\mathrm{Fe}_{3} \mathrm{O}_{4}$ nanoparticles with dimensions less than $30 \mathrm{~nm}$. Then, the synthetic nanocomposite material will give a larger surface area than the base material, which will be shown through the measurement of specific surface area by BET.

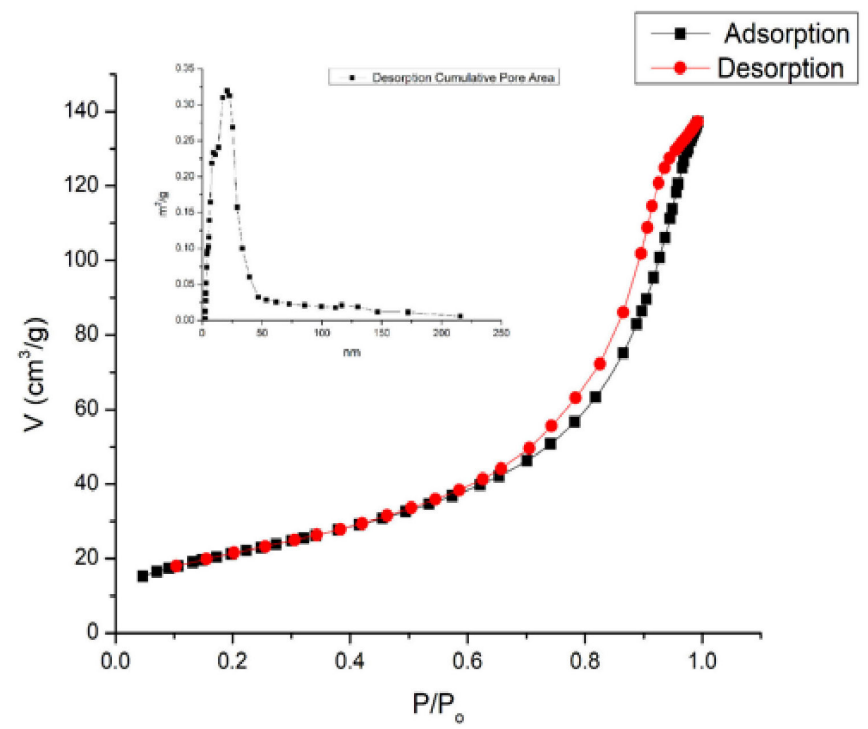

Figure 2. Nitrogen adsorption - desorption isotherms and Barrett-Joyner-Halenda (BJH) pore-size distribution for Talc, $\mathrm{Fe}_{3} \mathrm{O}_{4} / \mathrm{Talc}$ nanocomposite at $77 \mathrm{~K}$

From the results in (Figure 2), it is shown that the talc surface material has adsorption-desorption isotherm of the intermediate form between III and IV with the appearance of $\mathrm{H}_{3}$ hysteresis loop, $\mathrm{Fe}_{3} \mathrm{O}_{4} /$ Talc nanocomposite samples give adsorption-desorption isotherm of type IV and $\mathrm{H}_{3}$ hysteresis loop, rodshaped and letter-shaped according to IUPAC classification [19]. This allows the prediction that synthetic nanocomposite materials contain both large pores and medium pore, in which the medium pores are more numerous. The specific surface area of talc surface material is $3.45 \mathrm{~m}^{2} / \mathrm{g}$ which is much smaller than that of the nanocomposite material, which reachies $78.95 \mathrm{~m}^{2} / \mathrm{g}$. In particular, large pore area of the nanocomposite Smacro $=$ SBET - SBJH, ads - Smicro $=$ $=8.27 \mathrm{~m}^{2} / \mathrm{g}$; the pore diameter averages $11.8 \mathrm{~nm}$.

The magnetic properties of materials are assessed by the method of vibrating-sample magnetometry. The results for a material sample with near zero magnetic coercivity, with a saturation magnetization of
$32.4 \mathrm{emu} / \mathrm{g}$, this indicates that the survey sample is superparamagnetic, iron oxide particles is distributed with nano size on the soluble surface. Therefore, the material is convenient to separate from the aqueous solution after adsorption with the help of external magnetic fields [20].

\subsection{Adsorption process of $\mathrm{Cr}^{3+}$ on $\mathrm{Fe}_{3} \mathrm{O}_{4} / \mathrm{Talc}$ nanocomposite}

Effects of $\boldsymbol{p H}$ : The temperature is $24{ }^{\circ} \mathrm{C}$ for 60 minutes. Filter and determine the concentration of $\mathrm{Cr}^{3+}$ in the solution after adsorption.

The results in (Figure 3) show that when $\mathrm{pH}$ gradually increases, the adsorption capacity of lead increases, so the ability to treat lead contamination in water depends on the environmental $\mathrm{pH}$. However, the survey process was carried out from $\mathrm{pH}=4$ to $\mathrm{pH}=7$ because, at points of $\mathrm{pH}$ less than 4 , the dissolution of $\mathrm{Fe}_{3} \mathrm{O}_{4}$ nanoparticles occurs, in addition, at lower $\mathrm{pH}$, the adsorbate solution will be positively charged thus making $\mathrm{H}^{+}$ions compete effectively 
with $\mathrm{Cr}^{3+}$ cations, which may reduce lead adsorption [21], with $\mathrm{pH}$ greater than 7, the hydrolysis of chromium occurs. Therefore, subsequent surveys will be chosen with a $\mathrm{pH}$ value $=6.5$.

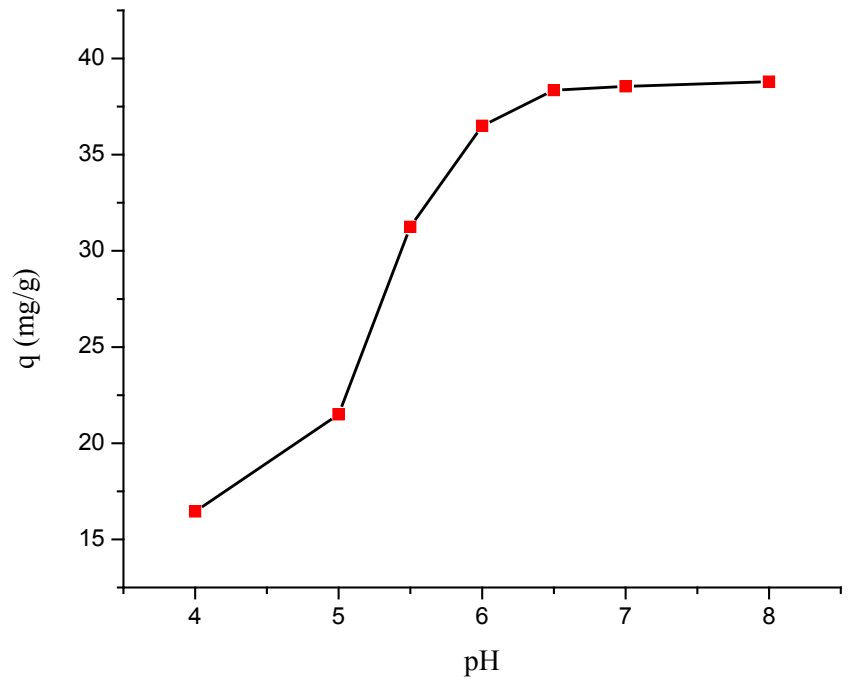

Figure 3. Effect of $\mathrm{pH}$ on adsorption of $\mathrm{Cr}^{3+}$ onto $\mathrm{Fe}_{3} \mathrm{O}_{4} / \mathrm{Talc}(50 \mathrm{ml}$ of $\mathrm{Cr}^{3+} 98.6 \mathrm{mg} / \mathrm{l}, 0.1 \mathrm{~g}$ sorbent)

Determining the time to reach adsorption equilibrium:

The $\mathrm{Cr}^{3+}$ survey solution has a concentration of $\mathrm{C}=106.5 \mathrm{mg} / \mathrm{l}$, adjusting solution's $\mathrm{pH}$ to $\mathrm{pH}=6.5$. Proceed on a magnetic stirrer at a speed of 140 $\mathrm{rev} / \mathrm{min}$, a temperature of $24^{\circ} \mathrm{C}$ during the time periods in turn: 5 to 120 minutes. Then, filter and collect the filtrate for survey.

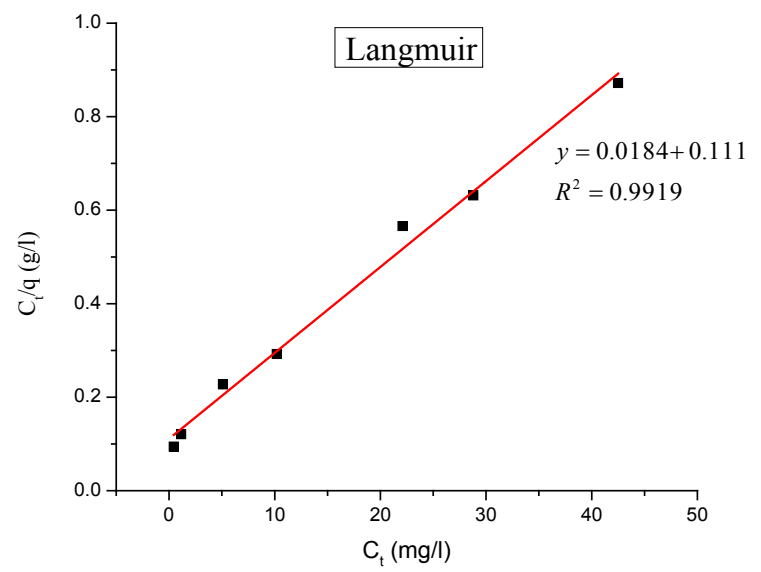

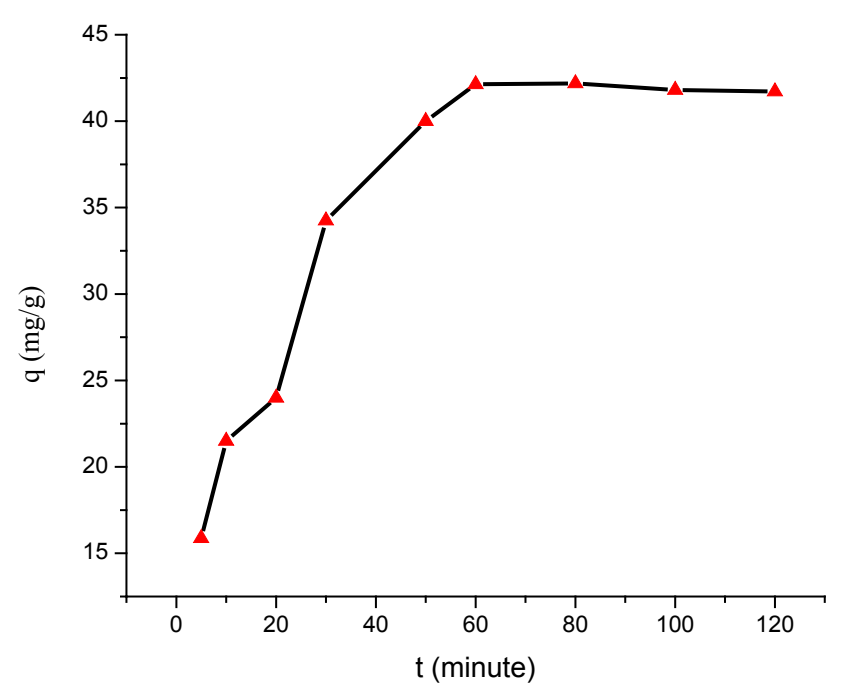

Figure 4. Effect of contact time on adsorption $\mathrm{Cr}^{3+}$ onto $\mathrm{Fe}_{3} \mathrm{O}_{4} / \mathrm{Talc}(50 \mathrm{ml}$ of $\mathrm{Cr}^{3+} 106.5 \mathrm{mg} / \mathrm{l}, 0.1 \mathrm{~g}$ sorbent)

Survey results show that, in the range of 5-60 minutes, the adsorption capacity of materials increases with adsorption time. After 60 minutes, the adsorption capacity is almost unchanged, so the time to reach adsorption equilibrium 60 minutes.

\section{Isothermal adsorption kinetics:}

The isothermal adsorption kinetics of the material is studied with two models of Langmuir and Freundlich $\mathrm{Fe}_{3} \mathrm{O}_{4} /$ Talc. The survey solution contains $\mathrm{Cr}^{3+}$ and $0.1 \mathrm{~g}$ of material to be stirred at a speed of $140 \mathrm{rev} / \mathrm{min}$, a temperature of $24^{\circ} \mathrm{C}$ for a period of 60 minutes. The isothermal adsorption model is given in (Figure 5).

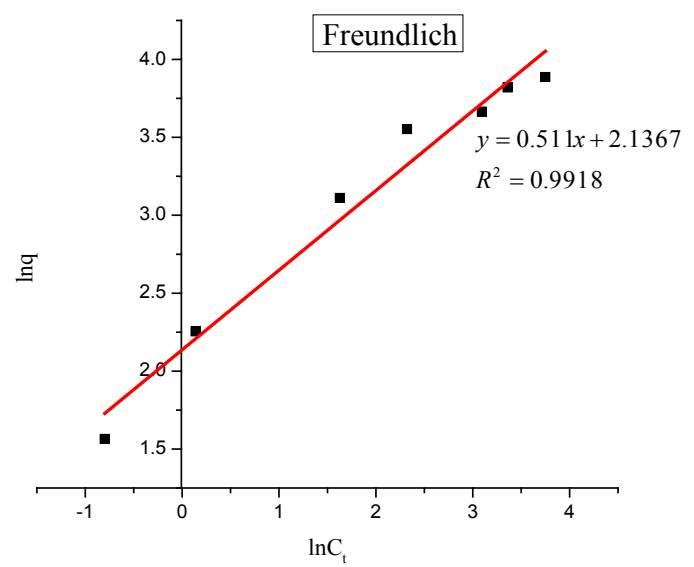

Figure 5. $\mathrm{Cr}^{3+}$ adsorption isotherm on $\mathrm{Fe}_{3} \mathrm{O}_{4} /$ Talc fitted to Langmuir and Freundlich 
Table 2. - Langmuir and Freundlich isotherm constants for the adsorption of $\mathrm{Cr}^{3+}$ ion by $\mathrm{Fe}_{3} \mathrm{O}_{4} / \mathrm{Talc}$

\begin{tabular}{|c|c|c|c|c|c|c|}
\hline \multicolumn{4}{|c|}{ Freundlich isotherm } & \multicolumn{3}{c|}{ Langmuir isotherm } \\
\hline $\mathbf{1} / \mathbf{n}$ & $\mathbf{n}$ & $\mathbf{K}_{f} \mathbf{m g} / \mathbf{g}$ & $\mathbf{R}^{\mathbf{2}}$ & $\mathbf{Q} \mathbf{m g} / \mathbf{g}$ & $\mathbf{K}_{\mathbf{L}} \mathbf{L} / \mathbf{m g}$ & $\mathbf{R}^{\mathbf{2}}$ \\
\hline 0.511 & 1.9566 & 8.4720 & 0.9918 & 54.3478 & $\mathrm{~K}=0.1658$ & 0.9919 \\
\hline
\end{tabular}

From the survey results fitted to Langmuir and Freundlich adsorption models, it is shown that the adsorption process of $\mathrm{Cr}^{3+}$ by $\mathrm{Fe}_{3} \mathrm{O}_{4} / \mathrm{Tall}_{\mathrm{c}}$ nanocomposite is more suitable with Langmuir model, however, with the absorption process also complies with the Freundlich isothermal equation. This shows that the synthetic material has adsorption centers with nearly the same surface energy. This shows that the lead adsorption process of $\mathrm{Fe}_{3} \mathrm{O}_{4} /$ Talc nanocomposite conforms to the Langmuir model in theory, but the empirical data also obeys the Freundlich model, which is due to the range of studied concentrations lies within the linear distribution range according to Freundlich model.

\subsection{Survey of adsorption kinetics}

The linear regression equations of $\ln \left(q_{e}-q_{t}\right)$ on $\mathrm{t}$ for first-order kinetic model, $\frac{t}{q_{t}}$ on $\mathrm{t}$ for second-
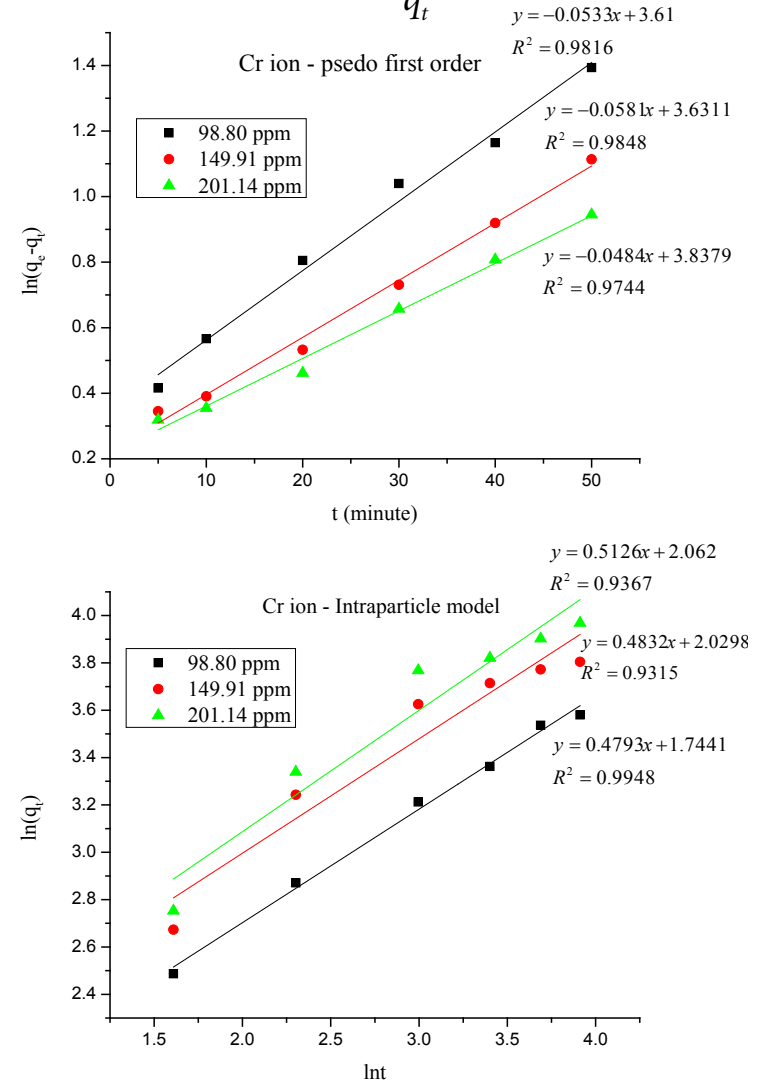

order kinetic model and $\ln \left(q_{e}\right)$ on $\ln (t)$ for diffusion kinetics model, $q_{t}$ on $\ln t$ for Elovich model are shown in (Figure 5). From the value of the slopes and the intercepts of the straight line equations, it is possible to calculate the respective kinetic equation constants given in (table 3), (figure 6).

From the results in (Table 3 ), it is shown that the quadratic equation of type 2 has a correlation coefficient of approximately 1 , furthermore, the values of the k constant are almost unchanged, which indicates that the speed constant does not depend on concentration. This proves that the adsorption process depends on the number of adsorption centers on the surface and the adsorbate is the $\mathrm{Cr}^{3+}$ ion.
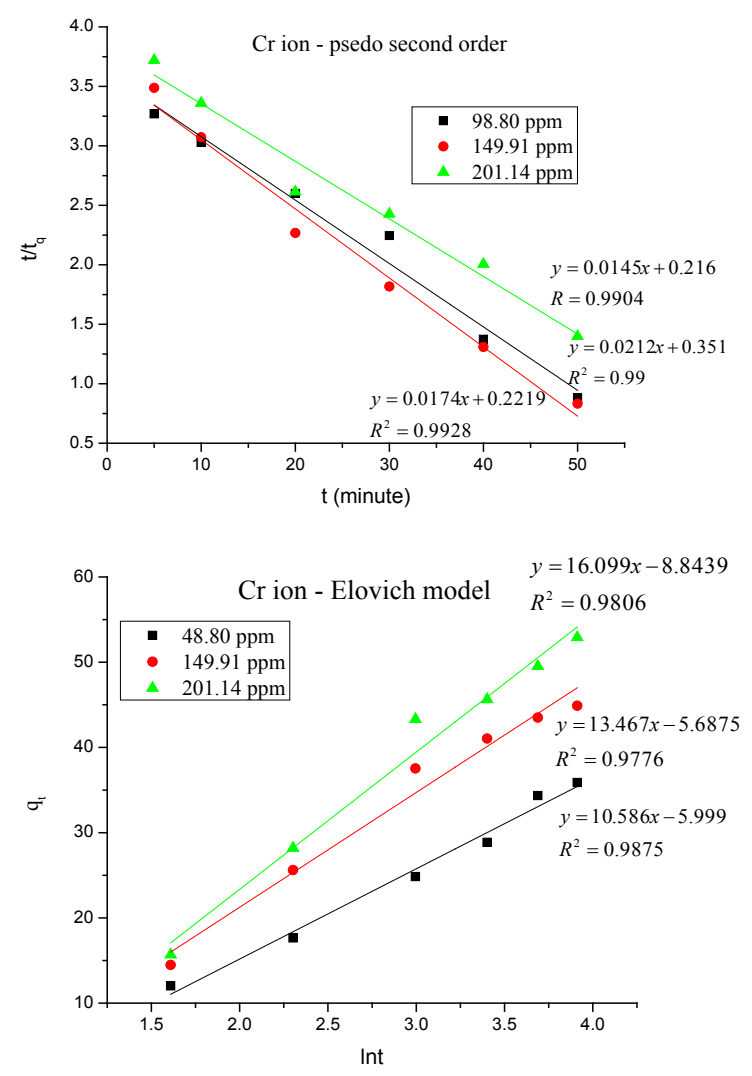

Figure 6. The kinetic models of adsorption of $\mathrm{Cr}^{3+}$ ion on the $\mathrm{Fe}_{3} \mathrm{O}_{4} / \mathrm{Talc}$ 
Table 3.- Kinetic parameters for the removal of $\mathrm{Cr}^{3+}$ onto $\mathrm{Fe}_{3} \mathrm{O}_{4} / \mathrm{Talc}$

\begin{tabular}{|c|c|c|c|c|c|c|c|c|c|}
\hline \multirow{2}{*}{$\begin{array}{c}\text { Co } \\
(\mathbf{p p m})\end{array}$} & \multicolumn{2}{|c|}{ Pseudo $\mathbf{1}^{\text {st }}$ order } & \multicolumn{2}{|c|}{ Pseudo $2^{\text {st }}$ order } & \multicolumn{2}{|c|}{$\begin{array}{c}\text { Intraparticle diffu- } \\
\text { sion }\end{array}$} & \multicolumn{3}{|c|}{ Elovich model } \\
\cline { 2 - 10 } & $\boldsymbol{R}^{\mathbf{2}}$ & $\boldsymbol{k}_{\mathbf{1}}$ & $\boldsymbol{R}^{\mathbf{2}}$ & $\boldsymbol{k}_{\mathbf{2}}$ & $\boldsymbol{R}^{\mathbf{2}}$ & $\boldsymbol{K}_{\boldsymbol{D}}$ & $\boldsymbol{R}^{\mathbf{2}}$ & $\boldsymbol{\alpha}$ & $\boldsymbol{\beta}$ \\
\hline 98.80 & 0.9816 & 0.0533 & 0.990 & 0.00128 & 0.9948 & 5.7208 & 0.9875 & -0.0149 & -0.1667 \\
\hline 149.91 & 0.9848 & 0.0581 & 0.9928 & 0.001364 & 0.9315 & 7.6126 & 0.9776 & -0.0193 & -0.1758 \\
\hline 201.14 & 0.9744 & 0.0484 & 0.9904 & 0.000973 & 0.9367 & 7.8618 & 0.9806 & -0.0013 & -0.1131 \\
\hline
\end{tabular}

\section{Conclusion}

The $\mathrm{Fe}_{3} \mathrm{O}_{4} /$ Talc nanocomposite was synthesized with the Talcum powder Phu Tho - Viet Nam by the chemical co-precipitaiton method. The reaction was carried out under a nonoxidizing oxygen-free. The surface area of the nanoparticles was determined to be $78.95 \mathrm{~m}^{2} / \mathrm{g}$ with an average diameter of $11.8 \mathrm{~nm}$ and the saturation magnetization of $32.4 \mathrm{emu} / \mathrm{g}$.

The experimental results indicate that the $\mathrm{Fe}_{3} \mathrm{O}_{4} /$ Talc nanocomposite is an effective adsorbent of $\mathrm{Cr}^{3+}$ ion from the aqueous solution. The adsorption equilibrium data fitted very well to the Langmuir and Freundlich adsorption isotherm models. The kinetic data showed that the adsorption process followed the pseudo-second order kinetic model.

The maximum adsorption capacities of $53.35 \mathrm{mg} / \mathrm{g}$ occurred at $\mathrm{pH} 6.5$ and $298 \mathrm{~K}$. These results permit us to conclude that $\mathrm{Fe}_{3} \mathrm{O}_{4} /$ Talc nanocomposite is a promising low-cost adsorbent for $\mathrm{Cr}^{3+}$ removal from wastewater and can be applied in a magnetically-assisted water treatment technology.

\section{References:}

1. Zayed A. M. and Terry N. Chromium in the environment: factors affecting biological remediation, Plant and Soil, 2003.- Vol. 249.- No. 1.- P. 139-156.

2. Helena Oliveira. Chromium as an environmental pollutant: Insights on induced plant toxicity, 2012. Journal of Botany, ID375843.

3. Grimm J., Bessarabov D., Sanderson R. Review of Electro-assisted methods for water purification, Desalination, 1998. 115,- P. 285-294.

4. Reena Singh, Neetu Gautam, Anurag Mishra, Rajiv Gupta. Heavy metals and living systems: An overview. Indian Journal of Phamacology, 2011.- Vol 43. 3,- P. 246-253.

5. Arezoo Azimi, Ahmad Azari, Mashallah Rezakazemi, Meisam Ansarpour. Removal of heavy metals from industrial wastewaters: A review. ChemBioEng, 2017. 4,- No. 1.- P. 1-24.

6. Giusy Lofrano, Giovanni Libralato, Jeanette Brow. Nanotechnologies for Environmental remediation: Applications and Implications, Spinger, 2017.

7. Abu Zayed M. Badruddoza and et al. $\mathrm{Fe}_{3} \mathrm{O}_{4}$ /cyclodextrin polymer nanocomposites for selective heavy metals removal from industrial wastewater. Carbohyrated polymers, 91, 2009.- P. 322-332.

8. Fanuel J Ligate, James E. G. Mdoe, Removal of heavy metal ions from aqueous solution using rice husksbased adsorbents. 2015. Tanz. J. Sci.- Vol. 41.- P. 91-102.

9. Amit Bhatnangar and etc. A review of the use of red mud as adsorbent for the removal of toxic pollutants from water and wastewater, Journal Environmental technology, 2011.- Vol 32.3,- P. 231-249.

10. Marco Bruno, Mauro Prencipe, Giovanni Valdre. Ab initio quantum-mechanical modeling of pyrophyllite $\left[\mathrm{Al}_{2} \mathrm{SiO}(\mathrm{OH})_{2}\right]$ and talc $\left[\mathrm{Mg}_{3} \mathrm{Si}_{4} \mathrm{O}_{10}(\mathrm{OH})_{2}\right]$ surfaces. Phys Chem Minerals, 2006. 33,- P. 63-71. 
11. Katayoon Kalantari and et al. Rapid adsorption of heavy metals by $\mathrm{Fe}_{3} \mathrm{O}_{4} / \mathrm{Talc}_{\mathrm{c}}$ nanocomposite and optimization study using response surface methodology. Int. J. Mol. Sci. 2014. 15, - P. 12913-12927.

12. Liu Wenlei, Zhao Shanlin, Cui Shuang, Zhang Jinhui, Li Ping \& Yang Shuangchun. Adsorptive characteristics of modified talcum powder in removing methylene blue from wastewater, Chemical Speciation and Bioavailability, 2014. 26(3),- P. 167-175.

13. Katayoon Kalantari, Mansor Bin Ahmad, Kamyar Shameli, Roshanak Khandanlou. Synthesis of talc/ $\mathrm{Fe}_{3} \mathrm{O}_{4}$ magnetic nanocomposites using chemical co-precipitation method. International Journal of Nanomedicine, 2013. 8,- P. 1817-1823.

14. Wan Ngah W.S., Fatinathan S.J. of Environmental Management. 2010.91,- P. 958-969.

15. Yuh-Shan Ho. Citation review of Lagergren kinetic rate equation on adsorption reactions, Scientometrics, 2004.- Vol. 59.- No. 1.- P. 171-177.

16. Ho Y.S. Adsorption of heavy metals from waste streams by peat, Ph. D. Thesis, University of Birmingham, 1995. U.K.

17. Ping Ge, Fenfting Li, Kinetics and Thermodynamic of heavy metal Cu (II) adsorption on mesoporous silicates, Polish J. of Environ.Stud, 2011. 20(2),- P. 339-344.

18. Abbas Sabah Thạeel, Isotherm, kinetic and thermodynamic of adsorption of heavy metal ions onto local activated carbon, Aquatic Science and Technology, 2013.- Vol. 1. - No. 2. - P. 53-77.

19. Matthias Thommes and et al. Physisorption of gases, with special reference to the evaluation of surface area and pore size distribution (IUPAC Technical Report), Pure Appl. Chem. 2015. 87(9-10): - P. 1051-1069.

20. Xinhua Xu et al., Nanoscale Zero-Valent Iron (nZVI) assembled on magnetic $\mathrm{Fe}_{3} \mathrm{O}_{4}$ /graphene for Chromium (VI) removal from aqueous solution, Journal of Colloid and Interface Science, 2014. 417,- P. 51-59.

21. Mahmood Iram, Chen Guo, Yueping Guan, Ahmad Ishfaq, Huizhou Liu. Adsorption and magnetic removal of neutral red dye from aqueous solution using $\mathrm{Fe}_{3} \mathrm{O}_{4}$ hollow nanospheres. Journal of Hazardous Materials. 2010. 181,- P. 1039-1050. 